\title{
Comparison of two potato simulation models under climate change. II. Application of climate change scenarios
}

\author{
Joost Wolf* \\ Group Plant Production Systems, Department of Plant Sciences, Wageningen University, PO Box 430, \\ 6700 AK Wageningen, The Netherlands
}

\begin{abstract}
The effects of climate change (for the year 2050 compared to ambient climate) and change in climatic variability on potato growth and production at 6 sites in Europe were calculated. These calculations were done with both a simple growth model, POTATOS, and a comprehensive model, NPOTATO. Comparison of the results from both models indicated the sort of climate change conditions in which model results differed and may become less reliable. The effectiveness of possible management responses to climate change and the uncertainty in the model results were also evaluated with both models. With both models, climate change in northern Europe resulted in moderate to strong tuber yield increases in Jokioinen, Finland, and Tylstrup, Denmark, and in almost no yield change in Oxford, UK, both with and without irrigation. NPOTATO calculated for climate change in central and southern Europe nil to slight decreases in irrigated yield for the HCGG climate change scenario and nil to moderate yield increases for the HCGS scenario, and variable changes in water-limited yield for the HCGG scenario and slight to moderate yield increases for the HCGS scenario. POTATOS calculated less positive or more negative changes in both irrigated and waterlimited yield by climate change in central and southern Europe than NPOTATO. With both models, changes in climatic variability did not result in changes in both irrigated and water-limited yields in Europe. The management response analyses showed that both cultivation of an earlier crop variety and an advanced planting date resulted in higher yields and in more positive or less negative yield change due to climate change, in particular in southern Europe, and that only in the case of an earlier planting date did irrigation requirements always decrease with climate change. This pointed to the need for advancing the planting date with climate change. The uncertainty analyses showed that the yield change due to climate change was practically not affected by the soil type, but that this yield change may become different when a different growth model is applied, a different planting date is chosen, or a different crop variety is used.
\end{abstract}

KEY WORDS: Climate change - Model comparison $\cdot$ Scenario analyses · Potato $\cdot$ Climatic variability · Risk assessment $\cdot$ Simulation model

\section{INTRODUCTION}

Climate change, which may result from increasing concentrations of greenhouse gases in the atmosphere (Mearns 2000), could considerably affect the growth

${ }^{*}$ Present address: Department of Soil and Land Use, ALTERRA Research Institute, Droevendaalse steeg 3, PO Box 47, 6700 AA Wageningen, The Netherlands.

E-mail: j.wolf@alterra.wag-ur.nl and yield of most crops (Adams et al. 1990, Easterling et al. 1992a,b). In the present study potato growth was simulated with 2 models under climate change conditions in Europe. The applied potato models are the simple POTATOS model (Spitters 1990, Kooman 1995, Kooman \& Spitters 1995) and the comprehensive NPOTATO model (Groot 1993, Wolf 2002 this issue). POTATOS has been tested against results from potato trials in Scotland (Kooman \& Spitters 1995), and has been applied to analyse observed differences in 
growth and yield of potato cultivars under a range of climatic conditions, from The Netherlands (Spitters 1987) to Tunisia and Rwanda (Kooman et al. 1996a,b), and to calculate the potential increases in tuber production of potato at the global scale (Van Keulen \& Stol 1995). NPOTATO has been developed within an EU project, CLIVARA (focussed on the effects of climate change and climatic variability on the growth and yield of four crop species in Europe; Downing et al. 2000), on the basis of a model for winter wheat, NWHEAT. A description of NPOTATO was given by Wolf (2002). The principles of NWHEAT and its application for analysing soil nitrogen supply and crop's nitrogen uptake during the growth period and for improvement of nitrogen application methods have been discussed by Groot \& De Willigen (1991) and Groot \& Spiertz (1991). A complete description of NWHEAT has been given by Groot $(1987,1993)$.

In the CLIVARA project both models have been applied to study the impacts of climate change on tuber production of potato at a number of sites in Europe (i.e. this study). POTATOS has also been used to calculate climate change impacts on potato production at national (Butterfield et al. 2000, Carter et al. 2000) and European scales (Harrison et al. 2000). Few other studies on the climate change impacts on potato production have been done. Within Europe, Peiris et al. (1996) studied the effects of future climate change on tuber production in Scotland and Davies et al. (1997) the effects on tuber production in England and Wales. For potato production in the USA, only Rosenzweig et al. (1996) has investigated the impacts of climate change.

Both models were calibrated and validated against results from experiments and variety trials in The Netherlands. Subsequently, the sensitivity of model results to separately changed values of weather variables was determined. These validation and sensitivity analyses were described by Wolf (2002). Both models were applied to analyse the possible effects of climate change in Europe on tuber production of potato. In addition to the mean change in climate, the variability of the climate may alter in the future (Rind et al. 1989, Mearns 2000). As mean crop yields may decrease with increasing climatic variability and the yield variability between years and the risk of a relatively low yield may concurrently increase (Semenov \& Porter 1995, Semenov et al. 1996), the possible effects of changes in climatic variability on tuber production were analysed too. Changed climate conditions may require a change in crop management, such as a change in planting date or a switch to a new variety. The effectiveness of such management responses to a changed climate were evaluated using the results from both models. The uncertainties that were incorporated in this climate change impact study were analysed.

\section{METHODOLOGY}

NPOTATO contains more elaborate descriptions of crop growth, assimilate allocation, leaf area expansion, phenology, senescence of crop organs, water balance, sink limitation, stress effects on assimilate production and allocation and on senescence than POTATOS. For a description of the main characteristics of both models, such as the main processes included and the input data required, see Wolf (2002). As the number of growth processes described in NPOTATO is much larger, the sensitivity to changes in environmental conditions may become more complex and may differ from that described in POTATOS.

For model simulations of future potato production, future weather data were required. Results from 2 of the Hadley Centre's climate model (HADCM2) transient experiments have been used to construct climate change scenarios for sites in Europe (Barrow et al. 2000). HADCM2 is a fully coupled ocean-atmosphere global climate model to investigate the response of the climate system to increasing levels of greenhouse gases and sulphate aerosols (Mitchell et al. 1995, Johns et al. 1997). The first HADCM2 experiment considered only the effects of increases in greenhouse gases on the climate (HCGG scenario) and the second experiment took into account both increases in greenhouse gases and in sulphate aerosols, which resulted in a smaller warming effect (HCGS scenario). The HCGG and HCGS climate changes (for the period around 2050) over Europe resulted in slight and variable changes in radiation, in slight increases in precipitation (except for a slight decrease in precipitation for HCGG climate change in southern Europe, mainly during summer), and in European-mean temperature rises of, respectively, 2.3 and $1.5^{\circ} \mathrm{C}$. These temperature rises varied between sites without clear patterns and were slightly stronger during winter than during summer.

Daily weather data as required for the future growth simulations, were produced with the LARS-WG stochastic weather generator (Semenov \& Barrow 1997). For each site, parameter values of the generator were first calibrated on the basis of historical weather data and subsequently adjusted on the basis of the site-specific climate change results from the HADCM2 experiments. Analyses of the daily data from the HADCM2 experiments allowed changes in climatic variability (in particular, changes in the standard deviation of the temperature data set and in wet and dry spell lengths) to be included in the generated weather data sets. For more information on this method for constructing climate change scenarios, see Barrow et al. (2000).

NPOTATO and POTATOS were applied at 6 sites in Europe. These sites cover the range of climatic 
conditions in Europe that is suitable for potato production: Jokioinen, Finland; Tylstrup, Denmark; Oxford,

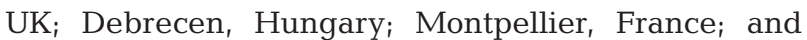
Bologna, Italy. For these sites the effects on potato production of climate change and change in climatic variability were calculated. The model simulations were made for $30 \mathrm{yr}$ of generated weather data for baseline climate (period around 1975), for $30 \mathrm{yr}$ of generated weather data for the HCGG and for the HCGS scenario climates (period around 2050), and for the latter scenario climates with incorporated changes in the climatic variability, i.e. HCGGv and HCGSv. For the baseline climate the atmospheric $\mathrm{CO}_{2}$ concentration was set at $353 \mathrm{ppmv}$ and for the 4 scenario climates at 515 ppmv. Reported values for each output variable are the mean result of $30 \mathrm{yr}$ of growth simulations.

Both applied models have been calibrated against experimental and variety trials with potato in The Netherlands (Wolf 2002). For the warmer sites the planting date is set earlier than for the cooler sites, ranging from Day 90 in Montpellier and Bologna to Day 125 in Jokioinen. For all sites the same potato variety (i.e. mid) and soil type (i.e. medium soil texture, such as loamy sand, with $75 \mathrm{~mm}$ maximum available water in rooted zone) were used.

\section{RESULTS}

Both models were applied to analyse the possible effects of climate change and changes in climatic variability on potato production. Changed climate conditions may require a change in crop management. The effectiveness of such management responses to a changed climate were evaluated using the results from both models. The uncertainties that were incorporated in this climate change impact study were analysed.

\subsection{Scenario analyses}

For irrigated production POTATOS calculated higher tuber yields for the baseline conditions at all sites than NPOTATO (Fig. 1). This difference in irrigated yield was also observed in the sensitivity analyses with both models (Wolf 2002). Both models calculated the lowest tuber yields for the baseline conditions at both the coolest (i.e. Jokioinen: short growing season) and warmest sites (i.e. Bologna: short growth period). Without irrigation, both models calculated similar yields for most sites (except for Debrecen). These yields were strongly affected by water shortage and were only half the irrigated yield level. Exceptions were the 2 most northern sites (i.e. Jokioinen and Tylstrup), where the yield reduction by water limitation was less severe.
The HCGG and HCGS scenarios for northern Europe resulted in strong tuber yield increases in Jokioinen, in slight to considerable increases in Tylstrup (with yield increases at both sites being generally very significant; Table 1), and in nil to slight yield increases (generally non-significant) in Oxford, both with and without irrigation (Fig. 1). Both potato models calculated almost similar yield changes with scenario climate change. Changes in climatic variability (HCGGv, HCGSv) in northern Europe resulted in no yield change when compared with the HCGG and HCGS results, both with and without irrigation and with both NPOTATO and POTATOS.

For the HCGG scenarios in central and southern Europe, NPOTATO calculated a slight decrease in irrigated tuber yields at Debrecen and Bologna and no yield change in Montpellier, and for the HCGS scenario no yield change at Debrecen and a slight to moderate increase at Bologna and Montpellier (Fig. 1). POTATOS calculated for the HCGG scenario a considerable decrease in tuber yield at Debrecen and Bologna and a moderate decrease in Montpellier (with decreases at the 3 sites being very significant; Table 1), and for the HCGS scenario a slight decrease in Montpellier and Bologna and a considerable decrease in Debrecen. Results from both models were quite similar, except for the higher yields under the baseline climate from POTATOS that resulted in stronger decreases in irrigated yield by climate change. The HCGS scenario resulted in smaller decreases and larger increases in irrigated yields than the HCGG scenario, with both NPOTATO and POTATOS. NPOTATO calculated for the HCGG scenario a slight decrease, no change and a moderate increase in water-limited tuber yield for, respectively, Debrecen, Bologna and Montpellier, and for the HCGS scenario a slight, a moderate and a moderate yield increase for the same sites. POTATOS calculated almost similar water-limited yields for the HCGG and HCGS scenarios as NPOTATO. As POTATOS calculated higher yields for baseline climate than NPOTATO, the changes in water-limited yield by scenario climate change in central and southern Europe from POTATOS were less positive or more negative than those from NPOTATO. Changes in climatic variability (HCGGv, HCGSv) in central and southern Europe resulted in no yield change when compared with the HCGG and HCGS results, both with and without irrigation and with both NPOTATO and POTATOS.

The coefficients of variation (CV) of irrigated tuber yields in northern Europe were calculated with the 2 models. CV values were relatively high under the cold baseline conditions in Jokioinen and decreased with scenario climate change (Fig. 2). CV values were low under both the baseline and scenario climates at Tylstrup 
A

Irrigated potato yields from POTATOS and NPOTATO

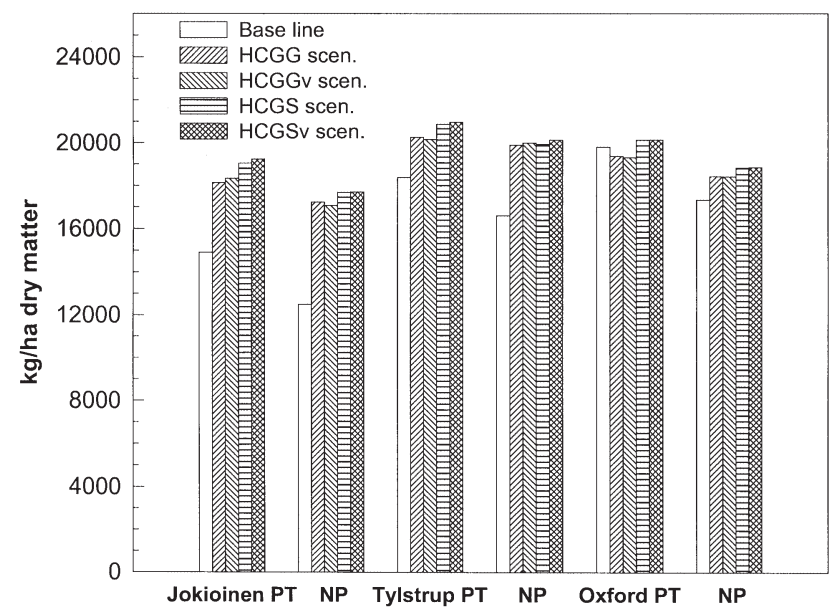

C Potato yield (not irrigated) from POTATOS and NPOTATO

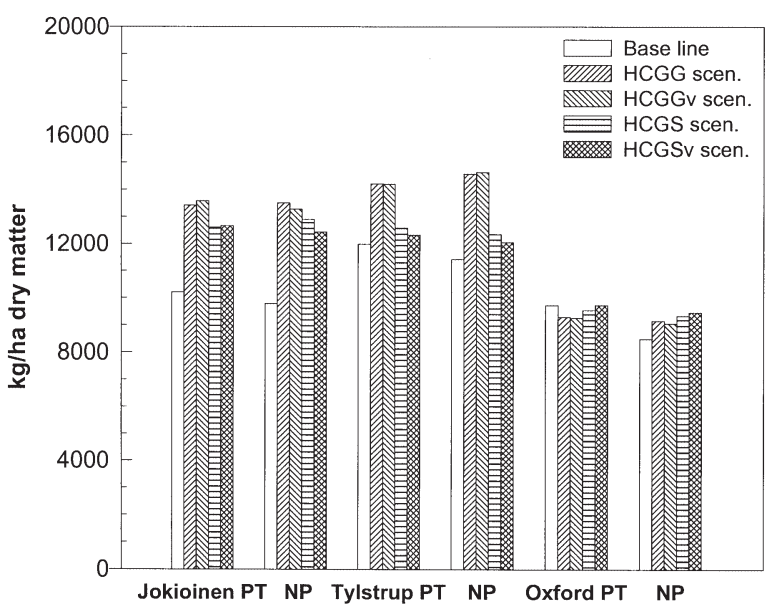

B Irrigated potato yields from POTATOS and NPOTATO

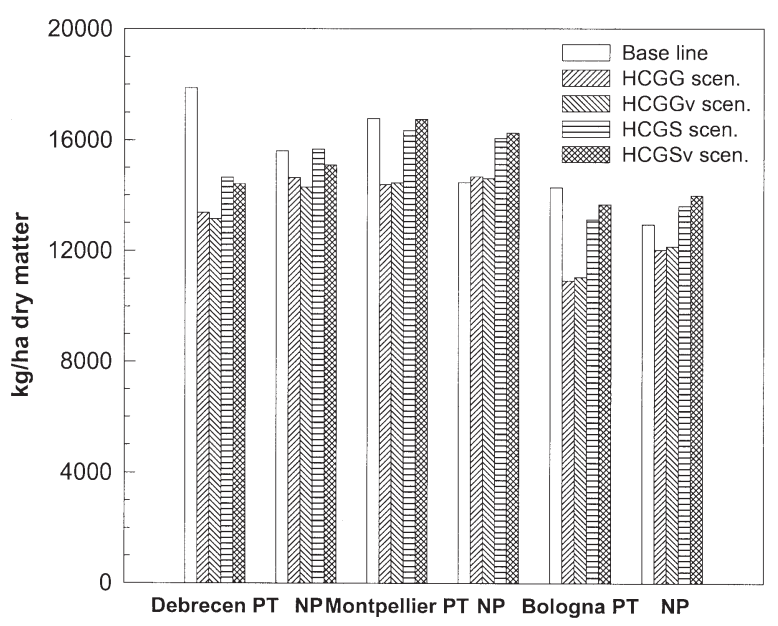

D Potato yields (not irrigated) from POTATOS and NPOTATO

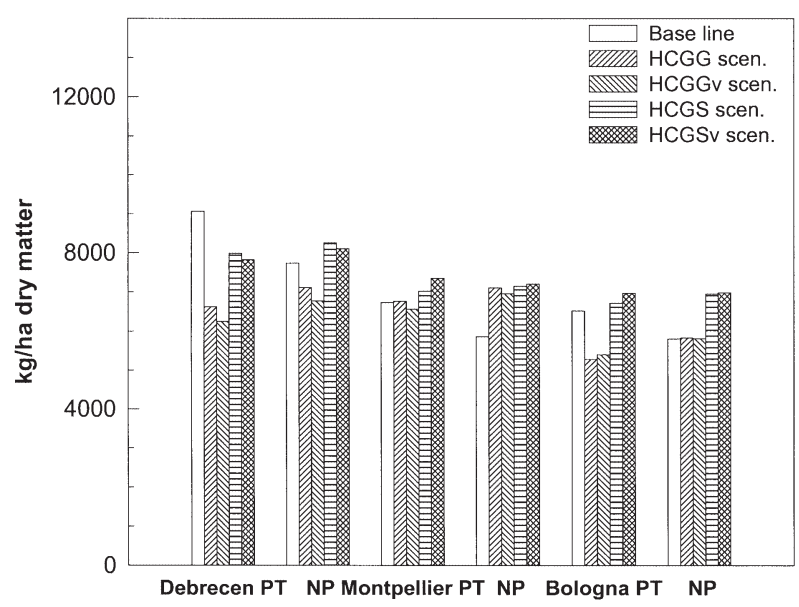

Fig. 1. Tuber yields of potato calculated with NPOTATO (NP) and POTATOS (PT) for present and future climate conditions at 6 sites in northern and southern Europe, both $(A, B)$ with and $(C, D)$ without irrigation. Results refer to 30 yr of generated weather data for baseline climate and 4 climate change scenarios

and Oxford and did not change with climate change. The CV values from both models were identical and a change in climatic variability almost did not change CV values of irrigated yields. Both models calculated a similar small decrease in CV values of water-limited tuber yield with scenario climate change at Jokioinen. POTATOS calculated CV values of water-limited yields under baseline climate at Tylstrup and Oxford that were lower than those from NPOTATO. POTATOS gave almost no change in CV with scenario climate change, whereas NPOTATO gave a nil to moderate decrease in $\mathrm{CV}$. Changes in climate variability changed CV values of water-limited yields to various extents, depending on site and climate change scenario, and these changes in CV were small and identical for the 2 models.
For the 3 sites in central and southern Europe the 2 models calculated slight to moderate and almost identical increases in CV of irrigated tuber yields with scenario climate change (Fig. 2). A change in climatic variability in the HCGG and HCGS scenarios resulted in a nil to slight increase and a nil to slight decrease in $\mathrm{CV}$ of irrigated tuber yield, respectively, with similar changes in CV from the 2 models. CV values of waterlimited production in southern Europe were higher than those in northern Europe, indicating a larger degree of water limitation. POTATOS calculated a slight decrease in $\mathrm{CV}$ of water-limited tuber yields with scenario climate change at Montpellier and no change and a slight increase in CV at Bologna and Debrecen, respectively. NPOTATO gave a slight 
Table 1. Statistical significance of the effect of climate change scenarios on tuber yields of potato calculated with POTATOS and NPOTATO for 6 sites (from north to south) in Europe. +: Positive changes in yield; -: negative changes; 0: no change. Double symbols indicate significance at the $1 \%$ level and single symbols at the $5 \%$ level. A: effect of climate change scenario in comparison to baseline climate; B: effect of change in climatic variability (e.g. HCGGv vs HCGG)

\begin{tabular}{|c|c|c|c|c|c|c|c|c|c|c|c|c|}
\hline & \multicolumn{6}{|c|}{ Irrigated production } & \multicolumn{6}{|c|}{ Non-irrigated production } \\
\hline & HCGG & HCGC & v HCGGv & HCGS & HCGSv & HCGSv & HCGG & HCGG & ICGGv & HCGS & HCGSv & HCGSv \\
\hline & & A & $\mathrm{B}$ & & $\mathrm{A}$ & B & & $\mathrm{A}$ & $\mathrm{B}$ & & $\mathrm{A}$ & $\mathrm{B}$ \\
\hline \multicolumn{13}{|l|}{ POTATOS } \\
\hline Jokioinen & ++ & ++ & 0 & ++ & ++ & 0 & ++ & ++ & 0 & ++ & ++ & 0 \\
\hline Tylstrup & ++ & ++ & 0 & ++ & ++ & 0 & ++ & ++ & 0 & 0 & 0 & 0 \\
\hline Oxford & 0 & 0 & 0 & 0 & 0 & 0 & 0 & 0 & 0 & 0 & 0 & 0 \\
\hline Debrecen & - & - & 0 & - & - & 0 & - & - & 0 & 0 & - & 0 \\
\hline Montpellier & - & - & 0 & 0 & 0 & 0 & 0 & 0 & 0 & 0 & 0 & 0 \\
\hline Bologna & - & - & 0 & - & 0 & 0 & - & - & 0 & 0 & 0 & 0 \\
\hline \multicolumn{13}{|l|}{ NPOTATO } \\
\hline Jokioinen & ++ & ++ & 0 & ++ & ++ & 0 & ++ & ++ & 0 & ++ & ++ & 0 \\
\hline Tylstrup & ++ & ++ & 0 & ++ & ++ & 0 & ++ & ++ & 0 & 0 & 0 & 0 \\
\hline Oxford & ++ & ++ & 0 & ++ & ++ & 0 & 0 & 0 & 0 & 0 & 0 & 0 \\
\hline Debrecen & - & - & 0 & 0 & 0 & 0 & 0 & 0 & 0 & 0 & 0 & 0 \\
\hline Montpellier & 0 & 0 & 0 & ++ & ++ & 0 & + & + & 0 & + & + & 0 \\
\hline Bologna & - & - & 0 & + & ++ & 0 & 0 & 0 & 0 & ++ & + & 0 \\
\hline
\end{tabular}

decrease in CV with climate change at all sites, which was mainly caused by the higher CV under the baseline climate.

\subsection{Management response analyses}

Changed climate conditions may require a change in crop management, such as a change in planting date or a switch to a new crop variety. Crop water use may also change, which in dry regions may have consequences for irrigation water requirements. The effectiveness of such management responses to a changed climate was evaluated using the results from both potato models.

\subsubsection{Crop variety}

Water-limited tuber yields were calculated with both models for the baseline and scenario climates at Bologna. These calculations were done for 3 (i.e. early, mid and late) potato varieties, mainly differing in thermal time requirements for their growth phases (Fig. 3). Both models calculated the highest yield under baseline conditions for the early crop variety. The HCGG and HCGS scenarios gave, respectively, nil and moderate increases in tuber yield with NPOTATO, and moderate and nil decreases with POTATOS. This more negative yield change due to climate change from POTATOS was mainly caused by the higher baseline yield from POTATOS than from NPOTATO. Both models calculated a slightly more positive or less negative yield change due to climate change for the earlier variety. These results show that under both baseline and scenario climate conditions an early potato variety should be grown. With both models, changes in climatic variability (HCGGv, HCGSv) did not give a yield change when compared with the HCGG and HCGS results.

\subsubsection{Planting date}

Irrigated and water-limited yields were calculated with both models for baseline and scenario climates at Bologna and for different planting dates (Fig. 4). An advanced planting date resulted in higher yields. This yield increase from both models became stronger with climate change. Although yields from POTATOS were more sensitive to planting date than those from NPOTATO, the relationship between yield change due to climate change and planting date was almost the same for the 2 models.

\subsubsection{Irrigation requirements}

The amount of irrigation water required for attaining the potential level of tuber production was calculated with both models for different sites in Europe, under both baseline and scenario climates (Table 2). POTATOS calculated moderately lower irrigation requirements for baseline conditions than NPOTATO (due to different evapo-transpiration method; Wolf 2002). The HCGG scenario resulted in higher irriga- 
A CV of irrigated potato yields from POTATOS and NPOTATO

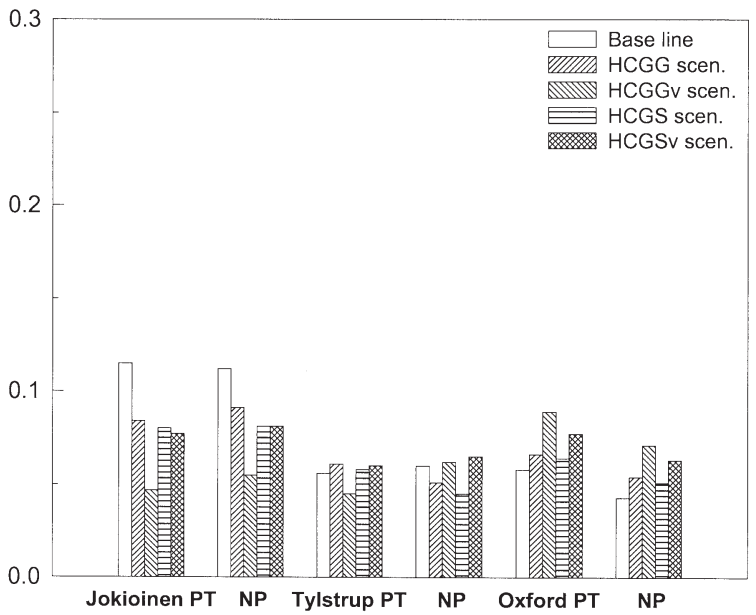

C

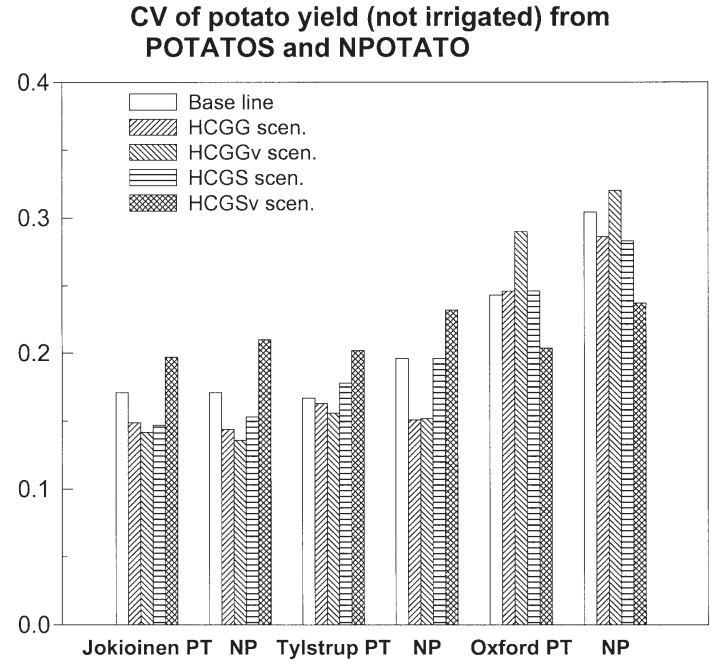

B CV of irrigated potato yields from POTATOS and NPOTATO

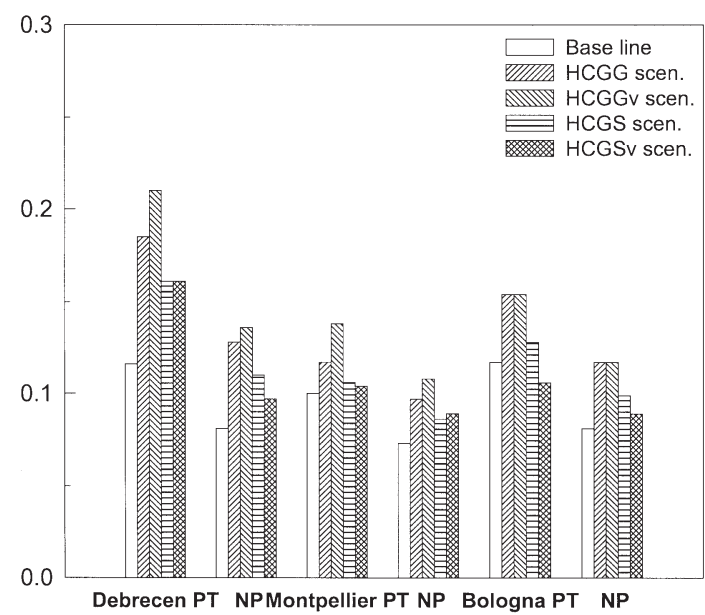

D

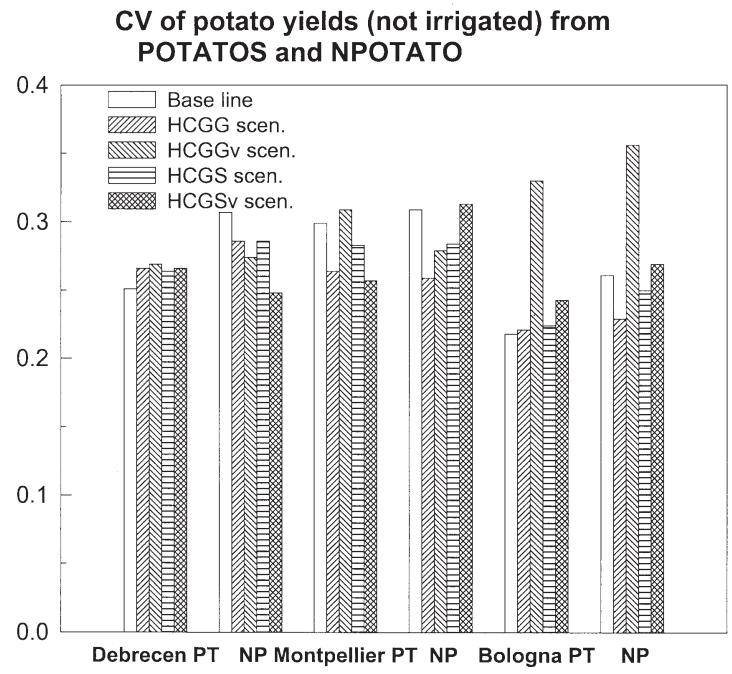

Fig. 2. Coefficient of variation (CV) of tuber yields of potato calculated with NPOTATO (NP) and POTATOS (PT) for present and future climate conditions at 6 sites in northern and southern Europe, both $(A, B)$ with and $(C, D)$ without irrigation. Results refer to $30 \mathrm{yr}$ of generated weather data for baseline climate and 4 climate change scenarios

A Potato yield (not irrigated) in Bologna from NPOTATO

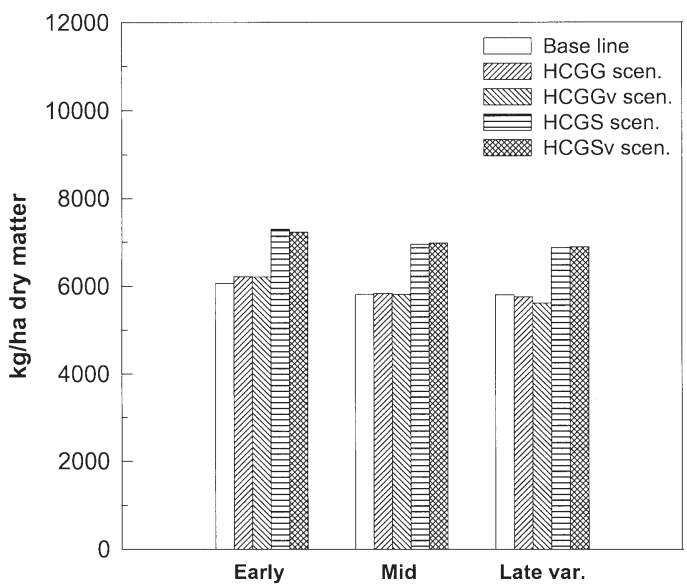

B Potato yield (not irrigated) in Bologna from POTATOS

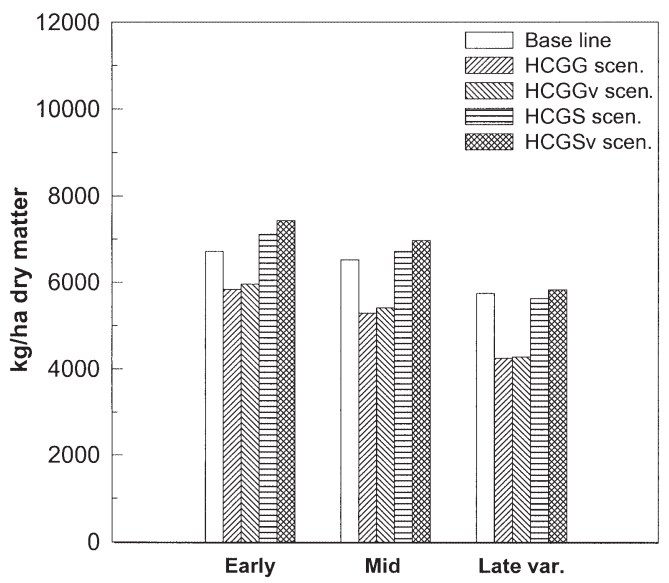

Fig. 3. Tuber yield of 3 potato varieties (early/mid/late; non-irrigated) calculated with (A) NPOTATO and (B) POTATOS for present and future climate conditions at Bologna. Results refer to $30 \mathrm{yr}$ of generated weather data for baseline climate and 4 climate change scenarios 
A

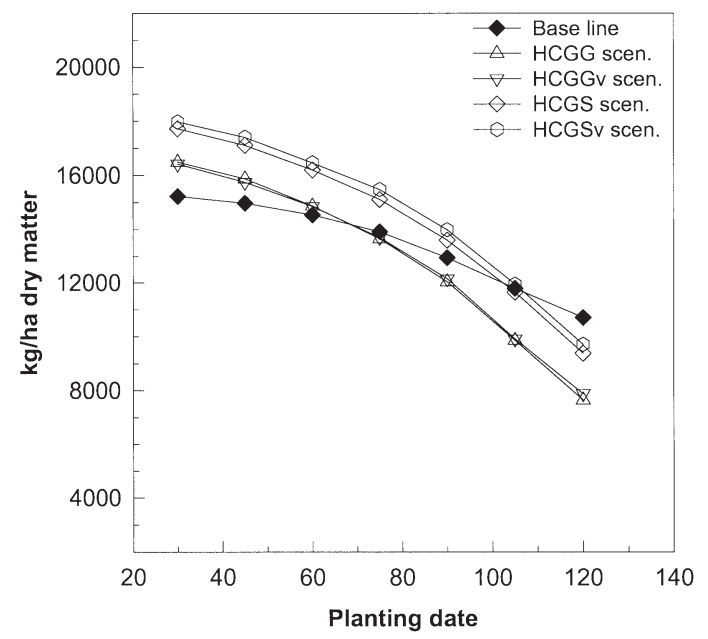

C

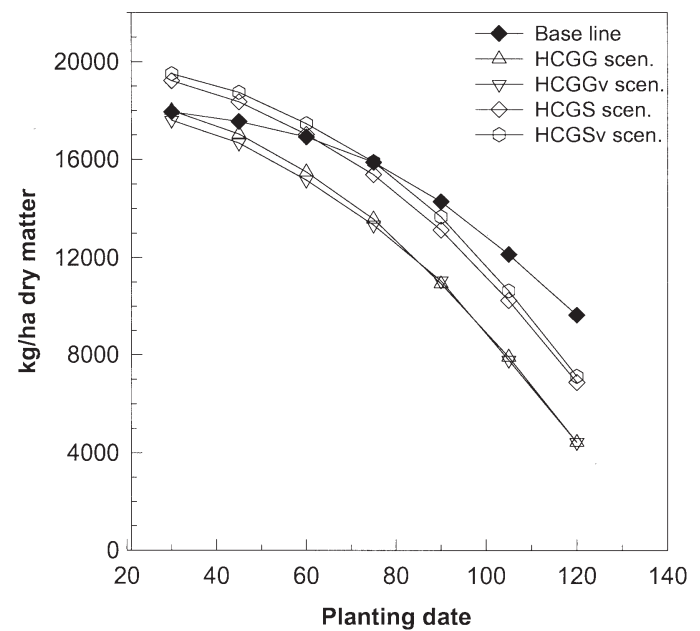

B Potato yield (not irrigated) in Bologna from NPOTATO

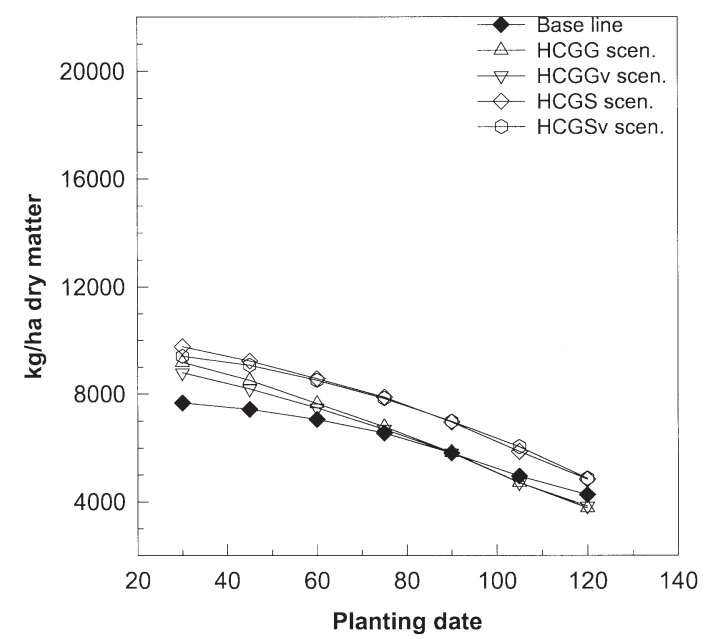

D Potato yield (not irrigated) in Bologna from POTATOS

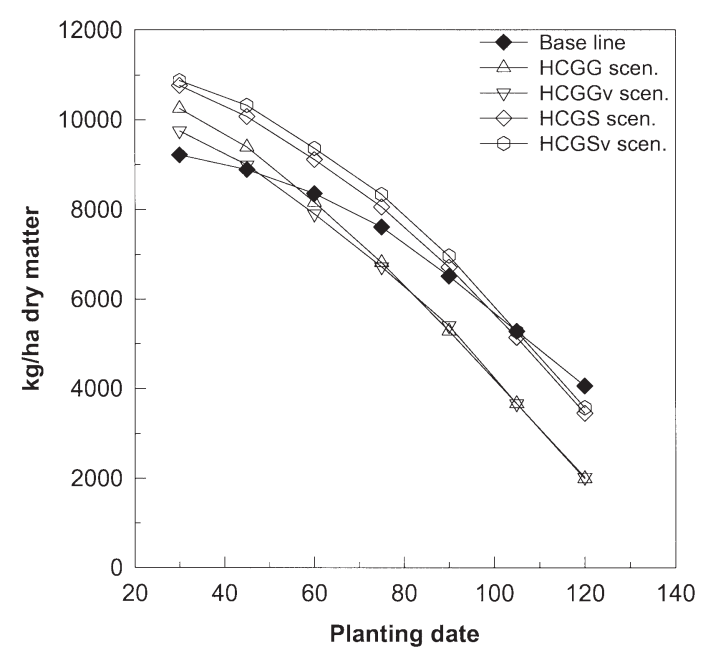

Fig. 4. Sensitivity to changes in planting date (Year day) of the tuber yields of irrigated and non-irrigated potato as calculated with $(A, B)$ NPOTATO and $(C, D)$ POTATOS for present and future climate conditions at Bologna. Results refer to 30 yr of generated weather data for baseline climate and 4 climate change scenarios

tion requirements for Debrecen, identical requirements for Oxford and Jokioinen, and lower requirements for Bologna, Tylstrup and Montpellier with NPOTATO and higher irrigation requirements for Oxford and lower requirements for the other 5 sites with POTATOS. This shows that POTATOS generally calculated a more negative change in irrigation requirements with the HCGG scenario climate change than NPOTATO. The HCGS scenario resulted in higher irrigation requirements for Jokioinen and Tylstrup, identical requirements for Oxford, and lower requirements for Bologna, Debrecen and Montpellier with NPOTATO, and higher irrigation requirements for Jokioinen, Oxford and Tylstrup, and lower require- ments for Bologna, Debrecen and Montpellier with POTATOS. Both models calculated almost identical changes in irrigation requirements with the HCGS scenario climate change for all sites except Debrecen and Oxford. With both models, a change in climatic variability (HCGGv, HCGSv) resulted in slightly negative to slightly positive changes in the irrigation requirements when compared with the HCGG and HCGS results.

The interaction between the change in irrigation requirements by climate change at Bologna and the planting date was studied with the 2 models. For an earlier and later planting day than the optimal date at present (i.e. Days 60 and 120) the HCGG scenario 
Table 2. Required amount of irrigation water $(\mathrm{mm})$ for attaining the potential tuber yield of potato on a soil with medium texture, calculated with NPOTATO and POTATOS for present and future climate conditions at 6 sites (from north to south) in Europe. Results refer to $30 \mathrm{yr}$ of generated weather data for baseline climate and for 4 climate change scenarios

\begin{tabular}{|c|c|c|c|c|c|c|c|}
\hline & \multirow[t]{2}{*}{ Site } & \multirow{2}{*}{$\begin{array}{c}\text { Planting } \\
\text { day }\end{array}$} & \multirow{2}{*}{$\begin{array}{l}\text { Baseline } \\
\text { climate }\end{array}$} & \multicolumn{4}{|c|}{ Climate change scenario } \\
\hline & & & & HCGG & HCGGv & HCGS & HCGSv \\
\hline \multirow{6}{*}{ NPOTATO } & Jokioinen & 125 & 182 & 181 & 185 & 205 & 208 \\
\hline & Tylstrup & 115 & 199 & 192 & 205 & 217 & 235 \\
\hline & Oxford & 105 & 261 & 261 & 268 & 261 & 258 \\
\hline & Debrecen & 105 & 341 & 354 & 355 & 332 & 334 \\
\hline & Montpellier & 90 & 378 & 359 & 375 & 359 & 363 \\
\hline & Bologna & 90 & 346 & 341 & 348 & 328 & 321 \\
\hline \multirow[t]{6}{*}{ POTATOS } & Jokioinen & 125 & 161 & 152 & 141 & 184 & 178 \\
\hline & Tylstrup & 115 & 174 & 166 & 177 & 200 & 211 \\
\hline & Oxford & 105 & 246 & 256 & 256 & 258 & 254 \\
\hline & Debrecen & 105 & 302 & 296 & 306 & 270 & 276 \\
\hline & Montpellier & 90 & 357 & 332 & 342 & 339 & 335 \\
\hline & Bologna & 90 & 307 & 287 & 293 & 277 & 280 \\
\hline
\end{tabular}

Table 3. Required amount of irrigation water $(\mathrm{mm})$ for attaining the potential tuber yield of potato on a soil with medium texture, calculated with NPOTATO and POTATOS for present and future climate conditions at Bologna and different planting dates (Year day). Results refer to $30 \mathrm{yr}$ of generated weather data for baseline climate and for 4 climate change scenarios

\begin{tabular}{|cccccc|}
\hline $\begin{array}{c}\text { Planting } \\
\text { day }\end{array}$ & $\begin{array}{c}\text { Baseline } \\
\text { climate }\end{array}$ & \multicolumn{5}{c|}{$\begin{array}{c}\text { Climate change scenario } \\
\text { HCGG HCGGv HCGS HCGSv }\end{array}$} \\
\hline $\begin{array}{c}\text { NPOTATO } \\
60\end{array}$ & 316 & 294 & 305 & 292 & 287 \\
90 & 346 & 341 & 348 & 328 & 321 \\
120 & 377 & 400 & 409 & 364 & 360 \\
POTATOS & & & & & \\
60 & 290 & 259 & 267 & 261 & 258 \\
90 & 307 & 287 & 293 & 277 & 280 \\
120 & 307 & 302 & 304 & 281 & 283 \\
\hline
\end{tabular}

resulted in a moderate decrease and a moderate increase in irrigation requirements, respectively, with NPOTATO and a moderate and a slight decrease, respectively, with POTATOS, and the HCGS scenario resulted in a moderate and a slight decrease, respectively, with NPOTATO and moderate decreases with POTATOS (Table 3). Future changes in irrigation requirements as a result of climate change appeared to be dependent on the chosen climate change scenario and the assumed planting date, and partly differed between the 2 models. However, an earlier planting date always reduced irrigation requirements for both the baseline and the scenario climates, to a considerable extent with NPOTATO and moderately with POTATOS.

\subsection{Model uncertainty analyses}

In this study, several uncertainties were incorporated. The following uncertainties and their possible effects on results of the climate impact study were analysed:

- model structure and modelled yield sensitivity;

- change in crop management (e.g. variety and planting date);

- quality of input data.

The structure of NPOTATO and POTATOS and their calibration and testing versus experimental data sets have already been described (Wolf 2002). The described differences between the 2 models and between their sensitivities of growth and yield to stepwise changes in climate gave an indication of the degree of uncertainty caused by the model structure. Under climate change the crop varieties best suited to an area may differ from the present varieties. Hence, growth simulations under climate change were conducted for different potato varieties. Also the effectiveness of other management responses to climate change (e.g. change in planting date) were evaluated and results were given above (Section 3.2).

The quality of the results from climate change impact studies is greatly dependent on the quality of the input data. The sensitivity of the yields to changes in weather data (indicating the sensitivity to data uncertainty) has been described in the sensitivity analysis (Wolf 2002). Soil information generally is available qualitatively and is often aggregated into mixed soil units. This results in uncertainty about the quantitative soil characteristics (e.g. rooting depth, water-holding capacity). Growth simulations under cli- 


\section{A Potato yield (not irrigated) in Bologna from NPOTATO}

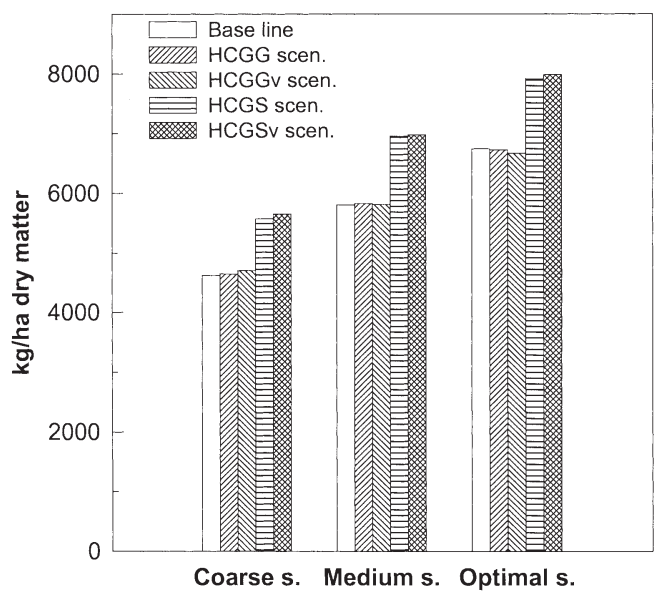

\section{B Potato yield (not irrigated) in Bologna from POTATOS}

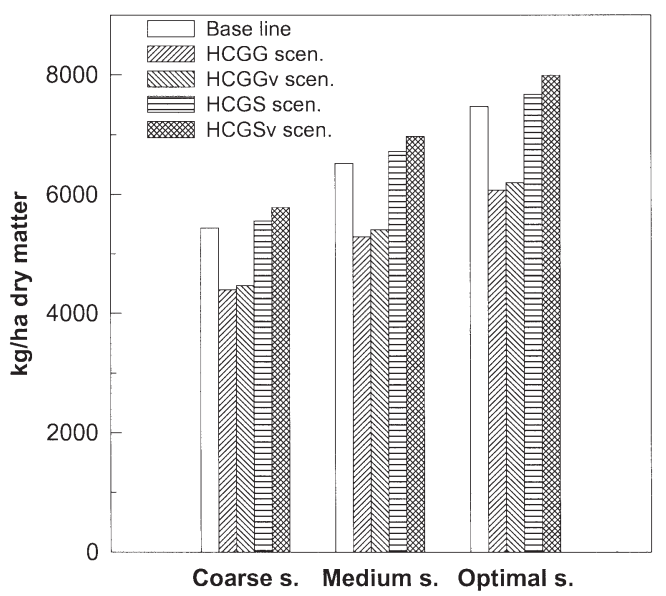

Fig. 5. Tuber yields of potato (non-irrigated) calculated with (A) NPOTATO and (B) POTATOS for 3 soil types and present and future climate conditions at Bologna. Results refer to $30 \mathrm{yr}$ of generated weather data for baseline climate and 4 climate change scenarios

mate change were conducted for different soil types to analyse this source of uncertainty.

Tuber yields of potato were calculated with both models for baseline and scenario climate at Bologna and for 3 soil types (Fig. 5), mainly differing with respect to the maximum available water in the rooted zone (coarse $=50 \mathrm{~mm}$, medium $=75 \mathrm{~mm}$, optimal $=$ $100 \mathrm{~mm}$ ). Yields considerably increased if the soils were able to supply more water, both under baseline and scenario climate. The yield change due to climate change was different for the different climate change scenarios (compared with baseline yield) and also differed between the 2 potato models. However, the impact of soil type on the yield change was nil.

\section{DISCUSSION AND CONCLUSIONS}

A simple model, POTATOS, and a comprehensive model, NPOTATO, were applied to analyse the possible effects of climate change and change in climatic variability on tuber production of potato in Europe. The comparison of the results from both models indicated the differences in their model approaches and the sort of environmental conditions in which the model results differed and may become less reliable.

Climate change in northern Europe resulted in moderate to strong tuber yield increases in Jokioinen and Tylstrup and in almost no yield change in Oxford, both with and without irrigation. Both models calculated almost similar yield changes. The yield increases were caused by the higher $\mathrm{CO}_{2}$ concentration and by the temperature rise but only at the most northern sites, as shown in the sensitivity analyses of this study (Wolf
2002). Peiris et al. (1996) calculated increases in tuber yield by temperature rise too for potato at a few sites in Scotland (with a climate similar to that at Jokioinen and Tylstrup); the yield increases likewise were due to faster crop emergence and canopy expansion and thus a longer growth period. For predicted future temperature rise (without an increase in atmospheric $\mathrm{CO}_{2}$ ) over England and Wales, Davies et al. (1997) calculated variable and little changes in tuber yield of maincrop potato, which were roughly similar to the yield change for Oxford in the present study. With both models, changes in climatic variability did not result in a yield change in northern Europe, both with and without irrigation.

NPOTATO calculated for climate change in central and southern Europe nil to slight decreases in irrigated tuber yield for the HCGG scenario and nil to moderate yield increases for the HCGS scenario. Under these climate change scenarios, the temperature rise had a negative effect on the tuber yields, which sometimes was stronger than the positive effect of $\mathrm{CO}_{2}$ enrichment. Irrigated yields from both models were almost the same, except for the higher yields under the baseline climate from POTATOS (as also observed in the sensitivity analyses; Wolf 2002). This resulted in stronger decreases in irrigated yield due to climate change from POTATOS. The HCGS scenario resulted in smaller decreases and larger increases in irrigated yields in central and southern Europe than the HCGG scenario with both models, which was due to the smaller temperature rise of the HCGS scenario. In a comparable study on the impacts of climate change on potatoes in the USA, Rosenzweig et al. (1996) calculated for most sites decreases in tuber yield due to the 
negative effect of temperature rise on yield that was stronger than the positive effect of $\mathrm{CO}_{2}$ enrichment. NPOTATO calculated for central and southern Europe variable changes in water-limited tuber yield for the HCGG scenario and slight to moderate yield increases for the HCGS scenario. POTATOS calculated yields for the scenarios quite similar to those of NPOTATO. As POTATOS calculated higher yields for the baseline climate than NPOTATO, the changes in water-limited yield by scenario climate change in central and southern Europe from POTATOS were less positive or more negative than those from NPOTATO. With both models, changes in climatic variability did not result in a yield change in central and southern Europe, both with and without irrigation. For other crops, such as soya bean, a change in climatic variability also did not result in a yield change (Wolf 2000).

The coefficient of yield variation (CV) is a good indicator of the yield variability between years and the risk of a relatively low yield. Climate change and changes in climatic variability may cause changes in the CV of tuber yield. The CV of irrigated tuber yields for baseline climate in both northern and southern Europe is low, and with climate change CV values slightly varied in northern Europe and slightly to moderately increased in southern Europe. This shows that optimal conditions for tuber production of potato occur at present in both northern and southern Europe and that with climate change conditions will become less favourable for potato production as southern Europe will become warmer (as also observed in the sensitivity analyses; Wolf 2002). The CV of water-limited tuber yields is higher than the $\mathrm{CV}$ of irrigated yields, particularly in central and southern Europe. This higher CV reflects the risk for yield reduction by drought for water-limited production. NPOTATO calculated a nil to moderate decrease in $\mathrm{CV}$ of water-limited yields with climate change in both northern and southern Europe. POTATOS, however, calculated a less negative or a more positive change in CV of water-limited yields, which was mainly caused by the lower CV under the baseline climate. Changes in climatic variability changed $\mathrm{CV}$ values of both irrigated and waterlimited yields to various extents, depending on site and climate change scenario, and these changes were in general small and identical for the 2 models.

The effectiveness of changes in crop management (i.e. variety, planting date, irrigation) in response to climate change was analysed. In southern Europe (i.e. Bologna), cultivation (without irrigation) of earlier crop varieties resulted in higher yields under baseline conditions and in more positive or less negative yield changes due to climate change according to both models, by starting earlier with tuber growth and by avoiding the hot and dry summer period. This shows that the crop variety had some effect on the yield change by climate change and that under both baseline and scenario climate conditions with hot and dry summers an early potato variety should be grown. An advanced planting date resulted in higher yields. According to both models, this yield increase was considerable in the present climate in southern Europe and became even larger under the scenario climate. This means that the yield change due to climate change became less negative or more positive by advancement of the planting date and that in response to climate change an earlier planting date was required, both with and without irrigation. Irrigation requirements both increased and decreased with climate change, depending on the site, the crop model and the climate change scenario, if planting occurred at the present date. However, the irrigation requirements always decreased with climate change if a much earlier planting date was used. This showed again the need for an advanced planting date with climate change. For soya bean too, this need for advancing the sowing date under climate change conditions in Europe, resulting in decreased irrigation requirements and stronger seed yield increases (Wolf 2000), was computed. For climate change conditions in the USA, Easterling et al. (1992b) also calculated positive yield changes for maize, soya bean and sorghum from advancing their sowing dates.

Uncertainties in this climate change impact study were analysed for Bologna. Such uncertainties arise from the quality of input data (e.g. weather and soil data), the assumed crop management, and the model structure and sensitivity. The differences between POTATOS and NPOTATO and the resulting differences in yield sensitivity to stepwise changes in climate (see Wolf 2002) gave an indication of the degree of uncertainty caused by the model structure. For example, the yield sensitivities to changes in most weather variables were practically similar for both models. Important model differences for irrigated production, however, were the lower yields for present conditions and the weaker and stronger yield increases with increasing radiation and atmospheric $\mathrm{CO}_{2}$ concentration, respectively, from NPOTATO compared with those from POTATOS. Without irrigation, the yield reduction by water shortage from NPOTATO was stronger than that from POTATOS. Uncertainties that were caused by the assumed crop management were described in the previous paragraph. For example, uncertainty about the crop variety used affected the yield change with climate change in most situations. The interaction between calculated yield change due to climate change and soil type was nil. This indicated that uncertainty about soil characteristics had almost no influence on the calculated yield change. For more 
extensive information on the various sources of uncertainty in climate change scenarios (e.g. uncertainty in greenhouse gas emission scenarios, in climate sensitivity to increasing greenhouse gas concentrations, in climate change patterns over Europe, and in changes in climatic variability) and in results from climate change impact studies (e.g. uncertainty in model approach, in model parameterization and calibration, and in input data that in particular increases in studies at the larger scale, such as studies on arable crop production under climate change conditions in Denmark [Olesen et al. 2000] and Finland [Carter et al. 2000]), see the proceedings of the ECLAT-2 workshop (Carter et al. 1999).

Acknowledgements. The author is grateful to all colleagues within the EU-project CLIVARA (see Downing et al. 2000) for the good collaboration and in particular to Elaine Barrow (Climatic Research Unit, University of East Anglia, UK) for providing the climate change scenarios. This work was funded by the Commission of the European Communities' Environment Programme (contract ENV4-CT95-0154).

\section{LITERATURE CITED}

Adams RM, Rosenzweig C, Peart RM, Ritchie JT and 6 others (1990) Global climate change and US agriculture. Nature 345:219-223

Barrow EM, Hulme M, Semenov MA, Brooks RJ (2000) Climate change scenarios. In: Downing TE, Harrison PA, Butterfield RE, Lonsdale KG (eds) Climate change, climatic variability and agriculture in Europe: an integrated assessment. Research report no. 21, Environmental Change Institute, University of Oxford, p 11-27

Butterfield RE, Harrison PA, Orr JL, Gawith MJ, Lonsdale KG (2000) Modelling climate change impacts on wheat, potato and grapevine in Great Britain. In: Downing TE, Harrison PA, Butterfield RE, Lonsdale KG (eds) Climate change, climatic variability and agriculture in Europe: an integrated assessment. Research report no. 21, Environmental Change Institute, University of Oxford, p 265-287

Carter TR, Hulme M, Viner D (eds) (1999) Representing uncertainty in climate change scenarios and impact studies. Proc ECLAT-2 Workshop, Report no. 1, Helsinki, Climatic Research Unit, University of East Anglia, Norwich

Carter TR, Saarikko RA, Joukainen SKH (2000) Modelling climate change impacts on wheat and potato in Finland. In: Downing TE, Harrison PA, Butterfield RE, Lonsdale KG (eds) Climate change, climatic variability and agriculture in Europe: an integrated assessment. Research report no. 21, Environmental Change Institute, University of Oxford, p 289-312

Davies A, Jenkins T, Pike A, Shao J, Carson I, Pollock CJ, Parry ML (1997) Modelling the predicted geographic and economic response of UK cropping systems to climate change scenarios: the case of potatoes. Ann Appl Biol 130: 167-178

Downing, TE, Harrison PA, Butterfield RE, Lonsdale KG (eds) (2000) Climate change, climatic variability and agriculture in Europe: an integrated assessment. Research report no. 21, Environmental Change Institute, University of Oxford
Easterling WE, McKenney MS, Rosenberg NJ, Lemon KM (1992a) Simulations of crop response to climate change: effects with present technology and no adjustments (the 'dumb farmer' scenario). Agric For Meteorol 59:53-73

Easterling WE, Rosenberg NJ, Lemon KM, McKenney MS (1992b) Simulations of crop responses to climate change: effects with present technology and currently available adjustment (the 'smart farmer' scenario). Agric For Meteorol 59:75-102

Groot JJR (1987) Simulation of nitrogen balance in a system of winter wheat and soil. Simulation Reports CABO-TT no. 13, DLO Research Institute for Agrobiology and Soil Fertility and Department of Theoretical Production Ecology, Wageningen Agricultural University

Groot JJR (1993) NWHEAT: nitrogen balance in a system of winter wheat and soil. In: Engel T, Klöcking B, Priesack E, Schaaf T (eds) Simulationsmodelle zur Stickstoffdynamik, Analyse und Vergleich. Agrarinformatik, Band 25. Ulmer, Stuttgart, p 397-411

Groot JJR, De Willigen P (1991) Simulation of the nitrogen balance in the soil and a winter wheat crop. Fertil Res 27: $261-272$

Groot JJR, Spiertz JHJ (1991) The role of nitrogen in yield formation and achievement of quality standards in cereals. In: Porter JR, Lawlor DW (eds) Plant growth: interactions with nutrition and environment. Society for Experimental Biology Seminar Series, Cambridge University Press, Cambridge, p 227-247

Harrison PA, Butterfield RE, Orr JL (2000) Modelling climate change impacts on wheat, potato and grapevine in Europe. In: Downing TE, Harrison PA, Butterfield RE, Lonsdale KG (eds) Climate change, climatic variability and agriculture in Europe: an integrated assessment. Research report no. 21. Environmental Change Institute, University of Oxford, p 367-390

Johns TC, Carnell RE, Crossley JF, Gregory JM, Mitchell JFB, Senior TA, Tett S, Wood RA (1997) The second Hadley Centre coupled ocean-atmosphere GCM: model description, spinup and validation. Clim Dyn 13:103-134

Kooman PL (1995) Yielding ability of potato crops as influenced by temperature and daylength. PhD thesis, Wageningen Agricultural University

Kooman PL, Spitters CJT (1995) Coherent set of models to simulate potato growth. In: Kabat P, Marshall B, Van den Broek BJ, Vos J, Van Keulen H (eds) Modelling and parameterization of the soil-plant-atmosphere system. A comparison of potato growth models. Wageningen Press, Wageningen, p 253-274

Kooman PL, Fahem M, Tegera P, Haverkort AJ (1996a) Effects of climate on different potato genotypes. 1. Radiation interception, total and tuber dry matter production. Eur J Agron 5:193-205

Kooman PL, Fahem M, Tegera P, Haverkort AJ (1996b) Effects of climate on different potato genotypes. 2. Dry matter allocation and duration of the growth cycle. Eur J Agron 5:207-217

Mearns LO (2000) Climatic change and variability. In: Reddy KR, Hodges HF (eds) Climate change and global crop productivity. CABI Publishing, Wallingford, p 7-35

Mitchell JFB, Johns TC, Gregory JM, Tett S (1995) Climate response to increasing levels of greenhouse gases and sulphate aerosols. Nature 376:501-504

Olesen JE, Jensen T, Bøcher PK (2000) Modelling climate change impacts on wheat and potato in Denmark. In: Downing TE, Harrison PA, Butterfield RE, Lonsdale KG (eds) Climate change, climatic variability and agriculture in Europe: an integrated assessment. Research report no. 
21, Environmental Change Institute, University of Oxford, p 313-332

Peiris DR, Crawford JW, Grashoff C, Jefferies RA, Porter JR, Marshall B (1996) A simulation study of crop growth and development under climate change. Agric For Meteorol 79:271-287

Rind D, Goldberg R, Ruedy R (1989) Change in climate variability in the 21st century. Clim Change 14:5-37

Rosenzweig C, Phillips J, Goldberg R, Carroll J, Hodges T (1996) Potential impacts of climate change on citrus and potato production in the US. Agric Syst 52:455-479

Semenov MA, Barrow EM (1997) Use of a stochastic weather generator in the development of climate change scenarios. Clim Change 35:397-414

Semenov MA, Porter JR (1995) Climatic variability and the modelling of crop yields. Agric For Meteorol 73:265-283

Semenov MA, Wolf J, Evans LG, Eckersten H, Iglesias A (1996) Comparison of wheat simulation models. II. Application of climate change scenarios. Clim Res 7: $271-281$

Editorial responsibility: Gerd Esser, Gießen, Germany
Spitters CJT (1987) An analysis of variation in yield among potato cultivars in terms of light absorption, light utilization and dry matter partitioning. Acta Horticult 214:71-84

Spitters CJT (1990) Crop growth models: their usefulness and limitations. Acta Horticult 267:349-368

Van Keulen H, Stol W (1995) Agro-ecological zonation for potato production. In: Haverkort AJ, MacKerron DKL (eds) Potato ecology and modelling of crops under conditions limiting growth. Current issues in production ecology, Vol 3. Kluwer Academic Publishers, Dordrecht, p $357-371$

Wolf J (2000) Modelling climate change impacts on soya bean in south-west Spain. In: Downing TE, Harrison PA, Butterfield RE, Lonsdale KG (eds) Climate change, climatic variability and agriculture in Europe: an integrated assessment. Research report no. 21, Environmental Change Institute, University of Oxford, p 217-237

Wolf J (2002) Comparison of two potato simulation models under climate change. I. Model calibration and sensitivity analyses. Clim Res 21:173-186

Submitted: June 11, 2001; Accepted: October 18, 2001

Proofs received from author(s): May 17, 2002 